\title{
Atributos físicos do solo e produtividade da soja em sistema de integração lavoura- pecuária com braquiária e soja
}

\author{
Soil physical attributes and soybean production in a crop-livestock integration system with \\ Brachiaria sp and Glycine max
}

\author{
Henrique Debiasi $^{{ }^{*}}$ Julio Cezar Franchini $^{\mathrm{I}}$
}

\section{RESUMO}

A integração lavoura-pecuária por meio da sucessão entre pastagem de braquiária no outono/inverno e culturas de grãos no verão constitui-se em uma opção para aumentar e diversificar a renda do produtor e melhorar a qualidade do sistema plantio direto. Com o objetivo de avaliar o efeito da época de dessecação da pastagem ou da pressão de pastejo por bovinos sobre atributos físicos do solo e a produtividade da soja em um sistema de integração lavourapecuária (SILP), foi conduzido um experimento sobre um Latossolo Vermelho Distroférrico. Nas parcelas principais, foram aplicadas pressões de pastejo equivalentes a 6,9; 9,4; e 16,5 unidades animais por hectare durante 19 dias em pastagem de Brachiaria brizantha $c v$. 'Xaraes', cuja fitomassa foi dessecada 30 dias antes da semeadura da soja (DAS). Também foram conduzidos tratamentos sem pastejo, nos quais a fitomassa foi dessecada aos 30, 44 e 52DAS. Foi determinada a fitomassa remanescente da pastagem, densidade, porosidade e resistência à penetração do solo e a produtividade das cultivares de soja 'BRS 294RR' e 'BRS 255RR', semeadas em subparcelas. As alterações nos atributos físicos do solo pelo pisoteio se concentraram na camada de 0,0-0,05m, contudo as maiores pressões de pastejo aumentaram o grau de compactação do solo até a camada de 0,2-0,3m. A produtividade da cultivar 'BRS 294RR' aumentou e a da cultivar 'BRS 255RR' não foi afetada pelo incremento da pressão de pastejo, demostrando que há diferença de resposta entre os genótipos ao grau de compactação do solo e, principalmente, à fitomassa remanescente da pastagem. A produtividade da soja em SILP com alta produção de matéria seca de B. brizantha é afetada pelo intervalo entre a dessecação da pastagem e a semeadura da cultura.

Palavras-chave: Glycine max, Brachiaria brizantha, manejo da pastagem, compactação do solo, sistema plantio direto.

\begin{abstract}
Crop livestock integration systems (CLIS) involving pastures of Brachiaria brizantha in autumn/winter and soybeans in summer have been considered an option to increase and diversify crop production and improve no-tillage system. This work aimed to evaluate the effect of grass desiccation timings or cattle grazing pressures on soil physical attributes and soybean yields in a crop-livestock integration system. The experiment was carried out on a dark red Latosol (Rhodic Eutrudox, US Soil Taxonomy) in southern Brazil. In the major plots, grazing pressures of 6.9, 9.4, and 16.5 animal unities per hectare were applied during 19 days to a pasture of Brachiaria brizantha $\mathrm{cv}$. 'Xaraes', which phytomass was desiccated 30 days before soybean sowing (DBS). Ungrazed plots were desiccated 30, 44 and 52 DBS. Remaining phytomass of the pasture; soil bulk density, porosity and soil resistance to penetration; and yield of soybean cultivars 'BRS 294RR' and 'BRS 255RR' (sowed in subplots), were determined. Changes in soil physical attributes by animal trampling were concentrated on topsoil layer (0.0$0.05 \mathrm{~m}$ ), and soil compaction level was increased by the highest grazing pressure down the 0.2-0.3 layer. The yield of soybean $c v$. 'BRS 294RR' was increased with rising grazing pressures, whereas the yield of soybean $\mathrm{CV}$. 'BRS 255RR' was not affected, showing that soybean genotypes had different responses to soil compaction level and, mainly, to remaining phytomass of pasture. In CLIS with high production of B. brizantha dry mass, soybean yields are closely associated to time interval between grass desiccation and soybean planting.
\end{abstract}

Key words: Glycine max, Brachiaria brizantha, grazing management, soil compaction, no-tillage system.

IEmbrapa Soja, Rodovia Carlos João Strass, s/n, CP 231, 86001-970, Londrina, PR, Brasil. E-mail: debiasi@cnpso.embrapa.br.

*Autor para correspondência. 


\section{INTRODUÇÃO}

O sistema de integração lavoura-pecuária (SILP) pode contribuir para a sustentabilidade da produção de soja nas diferentes regiões brasileiras, constituindo-se em uma opção para aumentar e diversificar a renda do produtor e melhorar a qualidade do sistema plantio direto (SPD). No entanto, um dos entraves à expansão da área sob SILP em regiões produtoras de soja é o receio dos produtores em relação à compactação do solo provocada pelo pisoteio dos animais no SPD.

A magnitude das alterações ocasionadas pelo pisoteio nos atributos físicos do solo é condicionada por vários fatores, entre os quais se destaca a intensidade de pastejo (FLORES et al., 2007). Quando a carga animal é adequada, a compactação pelo pisoteio se concentra na camada superficial do solo $(0,0-0,1 \mathrm{~m})$ (PETEAN et al., 2009) e não limita a produtividade das culturas (FLORES et al., 2007). Isso porque o uso de pressões de pastejo adequadas diminui a intensidade do pisoteio e mantém a cobertura do solo pela fitomassa da pastagem, o que pode dissipar parte da pressão aplicada ao solo, conforme comprovado por BRAIDA et al. (2006), em estudos envolvendo o efeito de diferentes quantidades de palha na densidade máxima do solo, obtida pelo Teste de Proctor Normal. Por outro lado, quando o pastejo é intenso e realizado em solos soltos e, ou, com umidade favorável à compactação, o pisoteio pode compactar o solo até 0,2m de profundidade (LANZANOVA et al., 2007), atingindo níveis críticos ao desenvolvimento das plantas (TREIN et al., 1991).

Poucas pesquisas têm sido realizadas no intuito de quantificar os efeitos da intensidade de pastejo sobre os atributos físicos do solo e a produtividade da soja em SILPs com forrageiras tropicais perenes, como as braquiárias. Essas espécies apresentam características que as diferenciam de forrageiras anuais de inverno, avaliadas na maioria dos trabalhos envolvendo intensidade de pastejo. Entre essas características, destaca-se a formação de touceiras maiores pelas forrageiras tropicais, o que, em conjunto com a menor população de plantas, pode resultar em um alto percentual de solo descoberto entre touceiras, aumentando a suscetibilidade do solo à compactação pelo pisoteio animal(MARCHÃO etal., 2007).

A pressão de pastejo também pode influenciar na produtividade da soja em função de seus efeitos sobre a dinâmica dos resíduos vegetais sobre o solo. O pastejo intensivo diminui a cobertura do solo durante o ciclo da pastagem e a cobertura por palha após sua dessecação, com implicações negativas na conservação do solo e da água. Por outro lado, em áreas sem ou com baixa pressão de pastejo, o excesso de fitomassa de Brachiaria spp. pode dificultar a semeadura e prejudicar o crescimento inicial da soja, em razão de efeitos alelopáticos (SOUZA et al., 2006) e de sombreamento do solo. Entretanto, é possível que esses efeitos sejam reduzidos pelo aumento do intervalo entre a dessecação e a semeadura da cultura.

O objetivo desta pesquisa foi avaliar o efeito da pressão de pastejo ou da época de dessecação da pastagem sobre alguns atributos físicos do solo e a produtividade da soja em um sistema de integração lavoura-pecuária com Brachiaria brizantha, cultivada como forrageira no intervalo entre dois ciclos da cultura de soja.

\section{MATERIAL E MÉTODOS}

O ensaio foi conduzido na Embrapa Soja em Londrina/PR ( $23^{\circ} 12^{\prime} \mathrm{S}, 51^{\circ} 11^{\prime} \mathrm{W}$ e altitude média de $585 \mathrm{~m}$ ), sobre um Latossolo Vermelho Distroférrico muito argiloso (respectivamente 787, 168 e 45g kg1 de argila, silte e areia), que vinha sendo cultivado sob SPD há quinze anos com soja no verão e trigo ou aveia preta no inverno. Antes da implantação do experimento, a área apresentava 32,2. $\mathrm{g} \mathrm{kg}^{-1}$ de matéria orgânica, 5,07

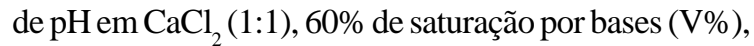
$22 \mathrm{mg} \mathrm{dm}^{-3}$ de $\mathrm{P}$ e, respectivamente, 0,58; 4,48; e $1,66 \mathrm{cmol}_{\mathrm{c}} \mathrm{dm}^{-3} \mathrm{de} \mathrm{K}$, Ca e Mg. Em agosto de 2008, foi realizada a semeadura direta de Brachiaria brizantha cv. 'Xaraes', utilizando-se semeadora tratorizada com espaçamento de $0,17 \mathrm{~m}$ entre linhas, regulada para distribuir $5 \mathrm{~kg} \mathrm{ha}^{-1}$ de sementes viáveis. A pastagem não foi adubada, sendo mantida sem pastejo até o início do experimento.

Em setembro de 2009, foram estabelecidos os seguintes tratamentos, dispostos em parcelas de 50 x 60m: P1 = pastejo com 6,9 unidades animais (UA) ha-1 ${ }^{-1}$ $\mathrm{P} 2$ = pastejo com 9,4UA ha-1; $\mathrm{P} 3$ = pastejo com 16,5UA ha ${ }^{-1}$; SP1 = sem pastejo, com dessecação da forrageira 52 dias antes da semeadura da soja (DAS); SP2 = sem pastejo, com dessecação aos 44DAS; e SP3 = sem pastejo, com dessecação aos 30DAS. Nas áreas pastejadas, a dessecação foi realizada aos 30DAS. Em todos os tratamentos, foi utilizado, para dessecação, o herbicida glifosato, na dose de 2,52kg i.a. ha-1. O delineamento experimental foi em blocos ao acaso com parcelas subdivididas e quatro repetições. Os animais, constituídos de bovinos machos e fêmeas sem padrão racial, entraram nos tratamentos pastejados em 15/09/ 2009, quando a massa de matéria seca (MMS) média da pastagem era 9,96Mg ha-1. O pastejo teve a duração de 19 dias, período no qual foi observada uma precipitação pluviométrica de $85 \mathrm{~mm}$. 
Nas subparcelas foram semeadas as cultivares de soja 'BRS 294RR' (grupo de maturidade 6.3) e 'BRS 255RR' (grupo de maturidade 6.7), utilizandose uma semeadora-adubadora tratorizada equipada com mecanismos sulcadores do tipo guilhotina para o adubo e discos duplos desencontrados para a semente. A semeadora foi regulada visando o estabelecimento de 350 mil plantas de soja por hectare, com espaçamento de $0,45 \mathrm{~m}$ entre linhas. A adubação de base equivaleu a $50 \mathrm{~kg} \mathrm{ha}^{-1}$ de $\mathrm{P}_{2} \mathrm{O}_{5}$ e de $\mathrm{K}_{2} \mathrm{O}$. As sementes foram inoculadas com Bradyrhizobium japonicum e $\boldsymbol{B}$. elkanii, estirpes SEMIA 587 e SEMIA 5019. Os tratos culturais e tratamentos fitossanitários foram realizados seguindo as indicações técnicas para a cultura na região.

No mesmo dia da dessecação, foi determinada a MMS remanescente da $\boldsymbol{B}$. brizantha por meio da coleta da fitomassa aérea em uma área de $0,25 \mathrm{~m}^{2}$ (0,5x0,5m), em três pontos por parcela, a qual foi seca em estufa a $65^{\circ} \mathrm{C}$ até massa constante, sendo os valores expressos em $\mathrm{Mg} \mathrm{ha}^{-1}$. Amostras de solo com estrutura preservada foram coletadas logo após a saída dos animais nos tratamentos P1, P2, P3 e SP3, utilizando-se anéis de aço inox com volume de $100 \mathrm{~cm}^{3}(5 \mathrm{~cm}$ de diâmetro interno e $5,1 \mathrm{~cm}$ de altura), inseridos horizontalmente no centro das camadas de 0,0-0,05, 0,05-0,1, 0,12-0,17, e 0,22-0,27m na parede de trincheiras abertas em cada parcela. Foram coletados cinco anéis por trincheira e camada. Em laboratório, foi determinada a densidade do solo (DS), a porosidade total (PT), a macroporosidade (MA) e a microporosidade (MI), conforme EMBRAPA (1997). A RP foi determinada até 0,3m de profundidade, empregando-se um penetrômetro de impacto modelo IAA/Planalsucar-Stolf. As leituras, espaçadas $0,1 \mathrm{~m}$, foram realizadas sobre um transecto de $2 \mathrm{~m}$ de comprimento, disposto transversalmente às linhas de semeadura no centro da parcela. Em cada transecto, foram coletadas amostras de solo nas camadas de 0,0-0,1, 01-0,2 e 0,2-0,3m de profundidade para determinação da umidade gravimétrica do solo (Ug). A produtividade da soja foi estimada por meio da colheita de três amostras de $27 \mathrm{~m}^{2}$ por subparcela, sendo os valores corrigidos para a umidade de $13 \%$ e expressos em $\mathrm{Mg} \mathrm{ha}^{-1}$.

Os dados foram submetidos à análise da variância (teste $\mathrm{F}, \mathrm{P}<0,05)$, sendo as médias agrupadas pelo critério de Scott-Knott $(\mathrm{P}<0,05)$, utilizando-se o programa SISVAR 4.3 (FERREIRA, 2008). As variáveis DS, PT, MA, MI e RP foram submetidas à análise multivariada para obtenção de um modelo de regressão em árvore (MRA) (DE’ATH, 2002), estimado com o uso do programa S-PLUS 2000. O MRA separa os tratamentos em grupos que se diferenciam entre si em função de um conjunto de variáveis. Em cada bifurcação do MRA, os fatores que ficam em lados opostos são diferentes e os que ficam do mesmo lado são iguais em relação aos atributos físicos avaliados. Para confirmar a existência de diferenças significativas entre os grupos formados pelo MRA, foi empregado o teste MRPP (Multi-Response Permutation Procedure) (MIELKE, 1991), utilizando-se o programa PC-ORD 5.00.

\section{RESULTADOS E DISCUSSÃo}

Na camada de 0,0-0,05m de profundidade, os atributos físicos do solo foram influenciados significativamente pelos tratamentos (Tabela 1). O tratamento sem pastejo com o mesmo intervalo entre a dessecação e a semeadura da soja (SP3) apresentou maiores valores de PT e MA em relação aos tratamentos pastejados, ocorrendo o inverso para a DS e a MI. As variáveis DS, PT, MA e MI não foram alteradas significativamente entre os tratamentos pastejados. Por outro lado, a maior pressão de pastejo resultou em incrementos significativos na RP na camada de 0,0$0,05 \mathrm{~m}$ apenas em relação à testemunha não pastejada. Os valores de Ug no momento da avaliação da RP foram similares entre os tratamentos $(\mathrm{P}<0,05)$, equivalendo, em média, a $0,31 \mathrm{~kg} \mathrm{~kg}^{-1}$ em todas as camadas avaliadas. Assim, os valores de RP provavelmente não foram influenciados por diferenças na Ug entre os tratamentos.

Esses resultados indicam que o pastejo, mesmo que por um período de tempo curto, aumentou o grau de compactação da camada superficial do solo, independentemente da carga animal utilizada. Comportamento similar foi obtido por FLORES et al. (2007) e PETEAN et al. (2009) em pastagem de aveia preta+azevém em Latossolos argilosos. ADS na camada de $0,0-0,05 \mathrm{~m}$ foi maior do que $1,30 \mathrm{Mg} \mathrm{m}^{-3}$ nas áreas pastejadas, valor considerado crítico ao desenvolvimento das plantas para o solo estudado (TORRES \& SARAIVA, 1999). Nessa camada, o valor médio de MA nos tratamentos pastejados foi de $0,04 \mathrm{~m}^{3}$ $\mathrm{m}^{-3}$, inferior ao limite crítico de $0,10 \mathrm{~m}^{3} \mathrm{~m}^{-3}$ definido por XU et al. (1992), revelando que a difusão de $\mathrm{O}_{2}$ às raízes pode ser comprometida, particularmente sob elevados potenciais de água no solo. Já a RP se aproximou de 3,5MPa, definido como valor crítico para penetrômetros de impacto por TORRES \& SARAIVA(1999), somente na maior pressão de pastejo.

Nas camadas de solo mais profundas, não houve efeito significativo da pressão de pastejo sobre os valores de DS, PT, MA, ME e MI. Porém, a RP apresentou diferenças significativas entre os tratamentos até a camada de 0,1-0,2m (Figura 1), 
Tabela 1 - Densidade do solo (DS), porosidade total (PT), macroporosidade (MA) e microporosidade (MI) em quatro camadas de um Latossolo Vermelho Distroférrico submetido a diferentes pressões de pastejo.

\begin{tabular}{|c|c|c|c|c|c|}
\hline Pressão de pastejo ${ }^{1}$ & DS & PT & MA & MI & $\mathrm{RP}$ \\
\hline $\mathrm{UA} \mathrm{ha}^{-1}$ & $\mathrm{Mg} \mathrm{m}^{-3}$ & --------------. & $-m^{3} m^{-3}-$ & ---------------- & MPa \\
\hline Sem pastejo (SP3) & $1,21 \mathrm{~b}$ & $\begin{array}{c}--0,00 \\
0,53 \mathrm{a}\end{array}$ & 0,09 a & $0,37 \mathrm{~b}$ & $1,72 \mathrm{~b}$ \\
\hline $6,88(\mathrm{P} 1)$ & $1,31 \mathrm{a}$ & $0,51 \mathrm{~b}$ & $0,06 \mathrm{~b}$ & 0,39 a & $1,98 \mathrm{~b}$ \\
\hline 9,38 (P2) & $1,32 \mathrm{a}$ & $0,50 \mathrm{~b}$ & $0,04 \mathrm{~b}$ & 0,39 a & $2,37 \mathrm{~b}$ \\
\hline 16,47 (P3) & $1,32 \mathrm{a}$ & $0,50 \mathrm{~b}$ & $0,03 \mathrm{~b}$ & $0,41 \mathrm{a}$ & $3,48 \mathrm{a}$ \\
\hline Média & 1,29 & 0,51 & 0,06 & 0,39 & 2,39 \\
\hline CV (\%) & 2,7 & 2,3 & 34,0 & 4,3 & 23,3 \\
\hline Sem pastejo (SP3) & $1,27 \mathrm{~ns}^{2}$ & $0,51 \mathrm{~ns}$ & $0,08 \mathrm{~ns}$ & $0,37 \mathrm{~ns}$ & $2,70 \mathrm{~b}$ \\
\hline 6,88 (P1) & 1,29 & 0,52 & 0,08 & 0,37 & $3.07 \mathrm{~b}$ \\
\hline 9,38 (P2) & 1,28 & 0,51 & 0,08 & 0,37 & $3,54 \mathrm{~b}$ \\
\hline 16,47 (P3) & 1,28 & 0,51 & 0,08 & 0,37 & 4,37 a \\
\hline Média & 1,28 & 0,51 & 0,08 & 0,37 & 3,42 \\
\hline CV (\%) & 2,1 & 1,6 & 12,4 & 2,5 & 16,78 \\
\hline Sem pastejo (SP3) & $1,26 \mathrm{~ns}$ & $0,51 \mathrm{~ns}$ & $0,08 \mathrm{~ns}$ & $0,37 \mathrm{~ns}$ & $3,24 b$ \\
\hline 6,88 (P1) & 1,27 & 0,51 & 0,08 & 0,37 & $3,24 \mathrm{~b}$ \\
\hline 9,38 (P2) & 1,26 & 0,51 & 0,09 & 0,37 & 3,46 a \\
\hline 16,47 (P3) & 1,28 & 0,51 & 0,08 & 0,37 & $3,51 \mathrm{a}$ \\
\hline Média & 1,27 & 0,51 & 0,08 & 0,37 & 3,33 \\
\hline CV (\%) & 2,1 & 1,8 & 18,7 & 3,2 & 6,52 \\
\hline Sem pastejo (SP3) & $1,20 \mathrm{~ns}$ & $0,52 \mathrm{~ns}$ & $0,08 \mathrm{~ns}$ & $0,37 \mathrm{~ns}$ & $3,10 \mathrm{~ns}$ \\
\hline $6,88(\mathrm{P} 1)$ & 1,23 & 0,52 & 0,08 & 0,36 & 3,12 \\
\hline 9,38 (P2) & 1,20 & 0,52 & 0,07 & 0,37 & 3,06 \\
\hline 16,47 (P3) & 1,24 & 0,51 & 0,07 & 0,38 & 3,20 \\
\hline Média & 1,22 & 0,52 & 0,08 & 0,37 & 3,12 \\
\hline CV (\%) & 3,7 & 2,1 & 19,9 & 2,7 & 6,0 \\
\hline
\end{tabular}

Médias seguidas por letras diferentes na coluna não diferem significativamente pelo teste de Scott-Knott $(\mathrm{P}<0,05) .{ }^{1} \mathrm{UA}$ ha ${ }^{-1}=$ unidades animais por hectare $(1 \mathrm{UA}=450 \mathrm{~kg}$ de peso vivo $) .{ }^{2} \mathrm{~ns}=$ diferenças estatisticamente não significativas (teste $\left.\mathrm{F}, \mathrm{P}>0,05\right)$.

mostrando-se um parâmetro mais sensível para avaliação do efeito do pisoteio sobre os atributos físicos do solo. Assim como na camada superficial, na camada de 0,05-0,1m apenas a maior pressão de pastejo resultou em incrementos significativos na RP em relação ao tratamento não pastejado. Já na camada de 0,1-0,2m, os valores de RP foram maiores para as pressões de pastejo P2 e P3 em relação à testemunha não pastejada e a menor carga animal (P1). Nas camadas entre 0,050,20m do tratamento P3, a RP superou o valor considerado limitante ao desenvolvimento radicular das culturas e com potencial para redução da produtividade (TORRES\& SARAIVA, 1999), especialmenteem anos secos.
A análise multivariada dos atributos físicos do solo por meio do MRA (Figura 1) proporcionou maior diferenciação entre os tratamentos, particularmente nas camadas mais profundas, mostrando-se uma ferramenta analítica mais sensivel às alterações provocadas pelo manejo do solo sob pastejo. O MRA separou os tratamentos e as camadas em onze grupos, os quais se diferenciam entre si em função dos valores de DS, PT, MA, MI e RP e, portanto, apresentam um grau de compactação diferente. O MRPP, por sua vez, confirmou a existência de diferenças significativas entre os grupos formados pelo MRA, à exceção do contraste entre os grupos 10 e 11. Na figura

Ciência Rural, v.42, n.7, jul, 2012. 


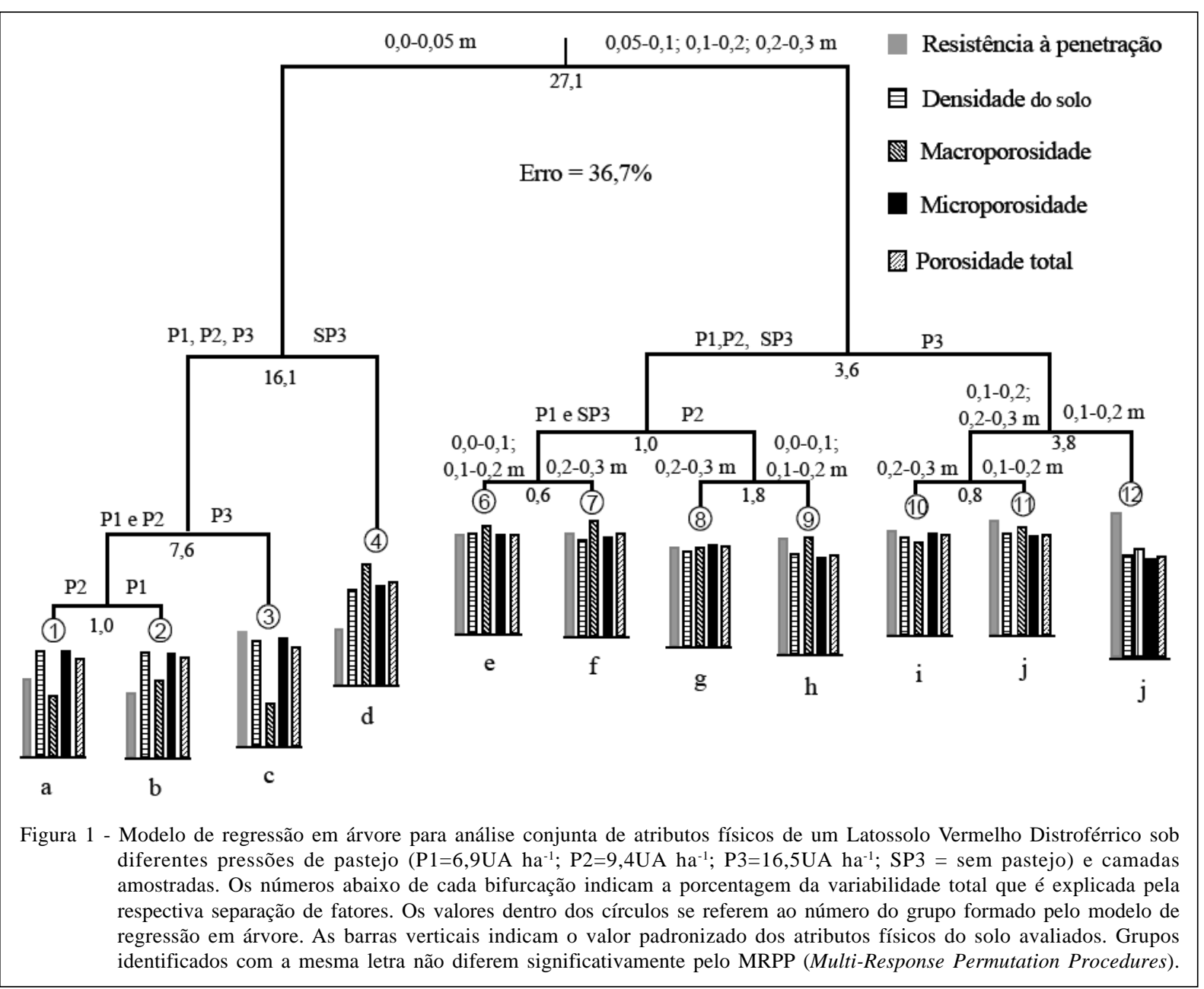

1 , as barras verticais representam os valores padronizados das variáveis dentro de cada grupo, o que permite comparar os grupos em função da magnitude de cada atributo físico estudado.

No lado esquerdo da primeira bifurcação, nota-se que a camada de 0,0-0,05m diferiu das demais, considerando-se os atributos físicos estudados (Figura 1). Nessa camada, os tratamentos foram separados em quatro grupos, demostrando que o pisoteio animal aumentou o grau de compactação do solo e esse incremento foi proporcional à pressão de pastejo. No lado direito da primeira bifurcação, nota-se que, para as demais camadas, o MRA resultou na formação de sete grupos que se diferenciam entre si em função dos valores de DS, PT, MA, MI e RP(Figura 1). A separação dos grupos mostra que a menor pressão de pastejo e a testemunha não pastejada não diferiram entre si, porém apresentaram um menor grau de compactação do que as demais pressões de pastejo. As maiores pressões diferiram entre si, sendo o grau de compactação proporcional à carga animal.
Esses resultados comprovam que o uso de altas pressões de pastejo, equivalentes a 9,4 e 16,5UA $\mathrm{ha}^{-1}$, mesmo que por um período curto, pode aumentar o nível de compactação do solo até a camada de 0,20,3m. Assim, o uso de uma carga animal compatível com a capacidade de suporte da pastagem e a resistência do solo à compactação é importante para manter a qualidade estrutural do solo, inclusive em camadas profundas. Dados similares foram obtidos por MARCHÃO et al. (2009) que, em pastagem de $\boldsymbol{B}$. ruziziensis cultivada em um Latossolo franco arenoso, observaram maiores valores de RP até $0,3 m$ nas áreas de concentração do pisoteio animal (trilhas). Da mesma forma, LANZANOVA et al. (2007), estudando diferentes sistemas de pastejo em pastagem de aveia preta+azevém, em um Argissolo franco-arenoso, observaram redução da MA até a camada de 0,10-0,15m no sistema com pastejo mais intenso.

Além da elevada pressão de pastejo, a umidade do solo e as características da forrageira podem ter favorecido o aumento da compactação do solo em 
maiores profundidades nos tratamentos P2 e P3. O pastejo foi realizado sob condições de elevada Ug, o que, além de torná-lo mais suscetível à compactação, aumenta a profundidade de transmissão das pressões aplicadas na superfície do solo (TARAWALLY et al., 2004). Por outro lado, por se tratar de uma forrageira cespitosa, a $\boldsymbol{B}$. brizantha se caracteriza por um alto percentual de solo descoberto entre as touceiras, o que facilita a compactação pelo pisoteio animal, devido à ausência da proteção proporcionada pela cobertura vegetal (BRAIDA et al., 2006).

Para a produtividade da soja, foi observada interação entre as cultivares e os tratamentos. A produtividade da cultivar 'BRS 255RR' não foi influenciada pelas pressões de pastejo e épocas de dessecação da testemunha não pastejada (Tabela 2). Por outro lado, a maior produtividade da cultivar 'BRS 294RR' foi obtida na maior pressão de pastejo, diferindo significativamente dos demais tratamentos pastejados e do tratamento SP3. Isso indica que a maior compactação do solo em função do pisoteio animal não foi suficiente para reduzir a produtividade da soja, mesmo quando os valores dos atributos físicos ultrapassaram os limites críticos para o desenvolvimento das plantas. Isso pode estar relacionado à distribuição regular das chuvas na safra 2009/2010, o que minimiza os efeitos negativos da compactação do solo sobre as plantas (TORRES \& SARAIVA, 1999).

A menor produtividade da cultivar 'BRS 294RR' nas menores pressões de pastejo e no tratamento sem pastejo com o mesmo intervalo entre a dessecação e a semeadura da soja (SP3) pode estar relacionada à elevada MMS de resíduos de $\boldsymbol{B}$. brizantha remanescentes após a dessecação (Tabela 2). Além de dificultar a semeadura, grandes quantidades de resíduos de braquiária podem reduzir o crescimento inicial da soja, devido à imobilização de nitrogênio e à liberação de compostos alelopáticos (SOUZA et al., 2006). É possível ainda que altos valores de MMS de B. brizantha remanescente após a dessecação tenham sombreado as plântulas de soja, dificultando o seu estabelecimento e crescimento.

O efeito negativo de grandes quantidades de fitomassa de $\boldsymbol{B}$. brizantha sobre o desenvolvimento da soja pode ser reduzido e/ou eliminado pelo aumento do intervalo entre a dessecação e a semeadura da cultura. Como consta na tabela 2, os tratamentos se diferenciaram em função da produtividade da cultivar 'BRS 294RR', sendo que o grupo caracterizado pelas menores produtividades envolveu os tratamentos dessecados aos 30DAS e cuja MMS de B. brizantha antes da dessecação era superior a $9 \mathrm{Mg} \mathrm{ha}^{-1}$. Já as maiores produtividades ocorreram nos tratamentos sem pastejo e dessecados aos 44 ou 52DAS e para o tratamento P3, que apresentava menor MMS por ocasião da dessecação.

\section{CONCLUSÃO}

O pisoteio animal aumenta o grau de compactação na camada superficial do solo e altas pressões de pastejo, mesmo durante um período curto, aumentam o grau de compactação até $0,3 \mathrm{~m}$ de profundidade. A produtividade da soja cultivar 'BRS 294RR' foi mais influenciada pela massa de matéria seca

Tabela 2 - Fitomassa de pastagem remanescente e produtividade das cultivares BRS 294RR e BRS 255RR de soja, em função da pressão de pastejo e da época de dessecação dos tratamentos não pastejados.

\begin{tabular}{|c|c|c|c|}
\hline \multirow{2}{*}{ Tratamento } & \multirow{2}{*}{ Fitomassa de pastagem remanescente } & \multicolumn{2}{|c|}{ Produtividade da soja } \\
\hline & & BRS 294 RR & BRS 255 RR \\
\hline \multicolumn{4}{|c|}{ - } \\
\hline \multicolumn{4}{|l|}{ Com pastejo ${ }^{1,2}$} \\
\hline 6,9UA ha ${ }^{-1}(\mathrm{P} 1)$ & $12,38 \mathrm{~b}$ & $3,03 \mathrm{~b}$ & $3,13 \mathrm{~ns}^{4}$ \\
\hline 9,4UA ha ${ }^{-1}(\mathrm{P} 2)$ & $9,10 \mathrm{~d}$ & $3,25 \mathrm{~b}$ & 3,08 \\
\hline $16,5 \mathrm{UA} \mathrm{ha}^{-1}(\mathrm{P} 3)$ & 5,55 e & 3,56 a & 2,77 \\
\hline \multicolumn{4}{|l|}{ Sem pastejo } \\
\hline Dessecação 52DAS ${ }^{3}$ (SP1) & $10,00 \mathrm{c}$ & 3,83 a & 2,94 \\
\hline Dessecação 44DAS (SP2) & $11,60 \mathrm{~b}$ & 3,60 a & 2,98 \\
\hline Dessecação 30DAS (SP3) & 14,15 a & $3,27 \mathrm{~b}$ & 3,08 \\
\hline CV (\%) & 11,0 & 6,1 & 6,4 \\
\hline
\end{tabular}

Médias seguidas pelas mesmas letras minúsculas na coluna não diferem significativamente pelo teste de $\mathrm{Scott}-\mathrm{Knnott}(\mathrm{P}>0,05)$. ${ }^{1} \mathrm{UA} \mathrm{ha}^{-1}=$ unidades animais por hectare $\left(1 \mathrm{UA}=450 \mathrm{~kg}\right.$ de peso vivo). ${ }^{2}$ Nos tratamentos com pastejo, a dessecação foi realizada aos $30 \mathrm{DAS} .{ }^{3}$ DAS $=$ dias antes da semeadura. ${ }^{4} \mathrm{~ns}=$ diferenças estatisticamente não significativas (teste $\mathrm{F}, \mathrm{P}>0,05$ ).

Ciência Rural, v.42, n.7, jul, 2012. 
de resíduos da pastagem do que pelas alterações nos atributos físicos do solo induzidas pelo pisoteio. A produtividade da soja aumenta com o aumento do intervalo entre a dessecação e a semeadura em sistemas com alta produção de massa de matéria seca de $\boldsymbol{B}$. brizantha cv. 'Xaraes'.

\section{REFERÊNCIAS}

BRAIDA, J.A. et al. Resíduos vegetais na superfície e carbono orgânico do solo e suas relações com a densidade máxima obtida no ensaio Proctor. Revista Brasileira de Ciência do Solo, v.30, p.605-614, 2006. Disponível em: <http://www.scielo.br/ s c i elo.ph p ? s c ript = s ci_art text \& pi d = S 0100 $06832006000400001 \& \operatorname{lng}=\mathrm{en} \& \mathrm{nrm}=\mathrm{iso}>$. Acesso em: $10 \mathrm{jul}$. 2011. doi: 10.1590/S0100-06832006000400001.

EMBRAPA. Centro Nacional de Pesquisa de Solos. Manual de métodos e análise de solo. 2.ed. Rio de Janeiro: CNPS, 1997. 212p.

DE’ATH, G. Multivariate regression trees: a new technique for modeling species-environment relationships. Ecology, v.83, n.4, p.1105-1117, 2002.

FERREIRA, D.F. SISVAR: um programa para análises e ensino de estatística. Revista Symposium, v.6, n.2, p.36-41, 2008.

FLORES, J.P.C. et al. Atributos físicos do solo e rendimento de soja em sistema plantio direto em integração lavoura-pecuária com diferentes pressões de pastejo. Revista Brasileira de Ciência do Solo, v.31, n.4, p.771-780, 2007. Disponível em: $<$ http://www.scielo.br/scielo.php?script=sci_arttext\&pid=S010006832007000400017\&lng=en\&nrm=iso>. Acesso em: 8 jul. 2011. doi: 10.1590/S0100-06832007000400017.

LANZANOVA, M.E. et al. Atributos físicos do solo em sistema de integração lavoura-pecuária sob plantio direto. Revista Brasileira de Ciência do Solo, v.31, p.1131-1140, 2007. Disponível em: $<$ http://www.scielo.br/scielo.php?script=sci_arttext\&pid=S010006832007000500028\&lng=en\&nrm=iso>. Acesso em: 8 jul. 2011. doi: 10.1590/S0100-06832007000500028.

MARCHÃO, R.L. et al. Qualidade física de um Latossolo Vermelho sob sistema de integração lavoura-pecuária no Cerrado. Pesquisa Agropecuária Brasileira, v.42, p.873-882, 2007. Disponível em:
<http://www.scielo.br/scielo.php?script=sci_arttext\&pid=S0100204X2007000600015\&lng=en\&nrm=iso >. Acesso em: 2 jun. 2010. doi: 10.1590/S0100-204X2007 000600015.

MARCHÃO, R.L. et al. Impacto do pisoteio animal na compactação do solo sob integração lavoura-pecuária no Oeste Baiano. Planaltina: Embrapa Cerrados, 2009. 6p. (Embrapa Cerrados, Comunicado Técnico, 163).

MIELKE, P.W., Jr. The application of multivariate permutation methods based on distance functions in the earth sciences. Earth-Science Reviews, v.31, p.55-71, 1991.

PETEAN, L.P. et al. Altura de pastejo de aveia e azevém e qualidade física de um Latossolo Vermelho distroférrico sob integração lavoura-pecuária. Semina: Ciências Agrárias, v.30, p.1009-1016, 2009. Disponível em: <http:// www.uel.br/ revistas/uel/index.php/semagrarias /article/view/4637/3943>. Acesso em: 26 maio, 2010.

SOUZA, L.S. et al. Efeito alelopático de capim-braquiária (Brachiaria decumbens) sobre o crescimento inicial de sete espécies de plantas cultivadas. Planta Daninha, v.24, p.657658, 2006. Disponível em: <http://www.scielo.br/ scielo.php? script = s ci_art text \& pid = S 0100 83582006000400006\&lng=en\&nrm=iso>. Acesso em: 22 jul. 2011. doi: 10.1590/S0100-83582006000400006.

TARAWALLY, M.A. et al. Field compaction at different soilwater status: effects on pore size distribution and soil water characteristics of a Rhodic Ferralsol in Western Cuba. Soil \& Tillage Research, v.76, p.95-103, 2004. Disponível em: <http://www.sciencedirect.com/science/article/pii/ S0167198703002241>. Acesso em: 19 jul. 2007. doi: 10.1016/ j.still.2003.09.003.

TORRES, E.; SARAIVA, O.F. Camadas de impedimento mecânico do solo em sistemas agrícolas com a soja. Londrina: Embrapa Soja, 1999. 58p. (Embrapa Soja, Circular Técnica, 23).

TREIN, C.R. et al. Métodos de preparo do solo na cultura do milho e ressemeadura do trevo, na rotação aveia + trevo/milho, após pastejo intensivo. Revista Brasileira de Ciência do Solo, v.15, p.105-111, 1991.

$\mathrm{XU}, \mathrm{X}$. et al. Compaction effects on the gas diffusion coefficients in soil. Soil Science Society of Amer ica Journal, v.56, p.1743-1750, 1992. 